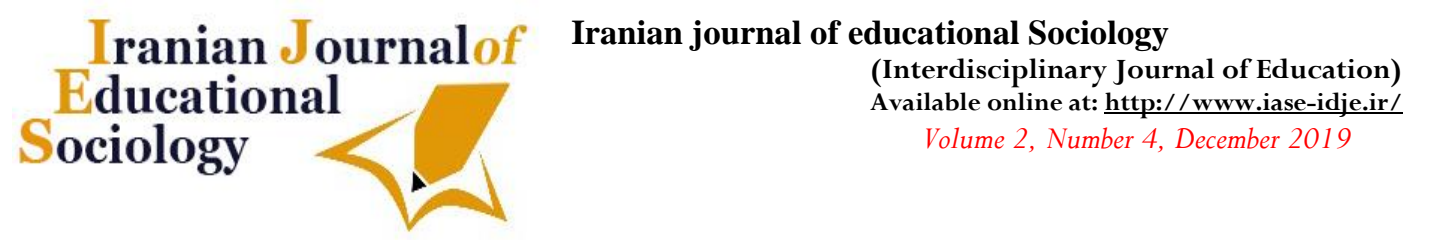

\title{
Design and Validation of Art Teaching Pattern in Elementary School of Iran
}

\author{
Zeinab Mirshekari ${ }^{1}$, Zohreh Saadatmand ${ }^{2 *}$, Narges Keshtiaray ${ }^{3}$ \\ 1. PhD Student, Department of Curriculum planning, Isfahan (Khorasgan) Branch, Islamic Azad University, Isfahan, Iran. \\ 2. Associate professor, Department of Curriculum planning, Isfahan (Khorasgan) Branch, Islamic Azad University, Isfahan, Iran. \\ 3. Associate professor, Department of Curriculum planning, Isfahan (Khorasgan) Branch, Islamic Azad University, Isfahan, Iran.
}

\section{Article history:}

Received date: 08 April 2019

Review date: 09 May 2019

Accepted date: 08 August 2019

\section{Abstract}

Purpose: The purpose of this research was to design and validate the appropriate art teaching model for elementary school students in Iran.

Methodology: The present study was descriptive-correlational in terms of applied purpose, correlational in terms of data collection and qualitative in terms of qualitative research method. This research was aimed at designing the model and using this qualitative method, the dimensions, components and indicators of the art teaching model were obtained. The statistical sample in the qualitative part of the study, ie in the method of thematic analysis, is 54 articles or dissertations or dissertations in this field, all of which have been studied. The present study was used by qualitative research method, thematic analysis method with exploratory inductive approach to extract themes and template formats. In the first stage of coding, the researcher discovered 8 comprehensive themes and 28 organizational themes and 71 basic themes. In the second coding, he discovered 7 comprehensive themes and 24 organizational themes and 65 basic themes. 7 comprehensive themes, 24 organizational themes and 61 basic themes have been obtained.

Findings: The results of the present study were a model based on 61 themes as basic themes and 24 organized themes and 7 comprehensive themes were extracted. Based on the results of this model, 7 indicators of art teaching model include teaching method index including group and individual dimensions, student index which includes dimensions of knowledge, attitude, skill, intelligence and thinking, teacher index which includes dimensions of teaching method, scientific development and promotion., An index of opportunities that includes the dimensions of culture, heritage, art and art in society, an index of weaknesses that includes the dimensions of parents, education, time, equipment and books and an index of strengths that includes upstream documents and the status of art and finally an index of principles that includes The principle of moderation, the principle of creation, the combination of art with goals and the principle of freedom.

Conclusion: By teaching art, you can explore children's skills, creativity, talent, intelligence, and imagination, and discover the hidden points in a child's mind and teach them to look at their surroundings with a new perspective and to realize their imaginations with their abilities.

Please cite this article as: Mirshekari Z, Saadatmand Z, Keshtiaray N. (2019). Design and validation of art teaching pattern in elementary school of Iran, Iranian journal of educational Sociology, 2(3): 143-157.

\footnotetext{
* Corresponding Author Email: zo.saadatmand@yahoo.com
} 


\section{Introduction}

In general, qualitative research deals with data that analyzes and analyzes the facts studied verbally, visually, or the like. This type of research emphasizes the meaning that relevant people (participants in the research process) have in mind about the phenomenon under study. In fact, qualitative research is the process of regular search in order to understand a social or human situation (Bazargan, 2016). Since the nature of this research is to teach art, it should be said that education in any society is one of the institutions influencing the process of human life, which is expected to be balanced and with a clear balance to various aspects of human existence. Pay attention to be able to provide the necessary opportunity for all-round growth of people. Sometimes, contrary to this expectation, it is seen that most educational systems, with a one-sided emphasis on cognitive features, ignore or pay less attention to other aspects of human existence. This onedimensional emphasis prevents the cultivation of the perfect human being, that is, the human being who has been nurtured and educated in the fields of belief, value, social, political, cultural, artistic, and moral. This is while having a balanced society depends on the validity of various human intelligences, talents and abilities within the education system, and belief in this diversity is the basis of policy, planning and fundamental action. Put society. One of the functions of education is to strive for the growth and flourishing of students' artistic and aesthetic abilities and talents. Because art, in its most stable and original manifestations, refers to the ideals, cognitions, skills, feelings, and deep and fundamental values that human beings rely on to achieve their real and original transformation, which results in their free and conscious transformation. It achieves values (Mehr Mohammadi, Kian, 2018).

Unlike many developed countries in the world, teachers seek to help students as creative people enter the labor market and society through education and art teaching. In other words, in developed countries, it is believed that by using and applying effective teaching and learning patterns in art, it provides grounds and infrastructures for creativity and divergent thinking in students (Sawyer, 2017). While in the Iranian education system, especially in primary education, this issue has not received much attention and has been carefully discussed and finally neglected in educational design, while research suggests that teachers as design Learners of Learning-Learning Opportunities, by using effective and efficient teaching patterns, promote students' creativity and educational innovations (Asensio-Pérez, et al., 2017), Because in the current situation, teachers not only need to learn how to use new technologies, but also need to use effective teaching models to actually realize the maximum potential of students and prepare them to activate their capacities (Ceresia, 2016).

Aesthetics and art is an area that requires teachers to take advantage of its capabilities for education and curricula, and if it is not used effectively in practice, it can lead to cultivation. Student aesthetics as well as its impact on nurturing other aspects will not be provided. Therefore, those involved in education in general, as well as teachers in more detail and in classrooms throughout the history of education or in different countries have tried to use this field, namely art and aesthetics for human education (Garmabi, Maleki, Beheshti, Afhami, 2015). Thus, art education and teaching are now considered by almost everyone as an important factor in educating people to enter and live in the 21st century (Taşdemir, 2010), because in the teaching process, how and where the teaching model exists. Appropriate and effective is more important than the content that is taught and taught (Winch, 2010; Dilekli, Tezci, 2016). In general, it can be said that art teaching as one of the functions of the educational system is related to the development of creative abilities, sensory and deep understanding of artistic phenomena, cultivating different senses, creating artistic phenomena, critical cognition and evaluation of symbolic visual forms, acquiring skills. They are related to artistic expression and expression, historical and cultural knowledge and development of sensitivity to aesthetic features (Amini, 2001).

From 1964 until the recent changes in the education system, the education system included a one-year pre-school preparation course, a five-year primary school course (primary school), a three-year secondary 
education course (middle school) and a four-year secondary education course (high school). Since 1992, the new secondary education system has replaced the previous system (Alaghband, 2018). According to the school's executive regulations, the primary school for a 6-year-old child in Iran begins with enrollment in the first grade. In most countries, children start school at the age of 6 or 7. From the academic year 201213, the sixth grade has been added to the elementary school of Iran. Elementary school teachers need to know how to set aside time for students and allow them to find their own way. The art course provides an opportunity to cultivate a sense of aesthetics and creativity and to learn and facilitate teach other subjects, to express emotions freely, to explore emotional and behavioral problems, to share intellectual endeavors, to express and present personal experiences, to soothe emotions, to develop values. And so it provides, in this regard, research has been done inside and outside the country.

In this regard, Ghaffari, Kazempou, Oghati Hamedani (2017) in a study entitled "The effect of disciplinary art education curriculum on art education of primary school students" concluded that the disciplinary art education curriculum in the field of production and art criticism on the level of art education Students have no effect, but the disciplinary art education curriculum in the field of art history and aesthetics affects students' artistic education. Farsi and Nouri (2016) in a study entitled "Evaluation of elementary school art curriculum through expertise and educational critique" concluded that painting and handicrafts are the only content areas that are taught in art classrooms and often with explanatory methods. . In addition, in evaluating artistic activities, various and varied assessment tools and methods are not used and individual differences between students are not considered. Due to the lack of trained manpower in the field of art education and their insufficient familiarity with the principles of art teaching, it is necessary to hold training courses for teachers as well as training art teachers specializing in art education in teacher training institutes and faculties of educational sciences.

In line with these findings, Ghanbari, Hemmati (2016) in a study entitled "Content analysis of the curriculum of art in the first grade of elementary school in terms of attention to aesthetic components by content analysis method" showed that in the curriculum of art in the first grade Until the elementary school, attention has been paid to the components of aesthetics. Garmabi, et al (2015) in a study entitled designing and validating the pattern of the elementary school curriculum based on the components of aesthetics and art examined the components of aesthetics in the curriculum of the elementary school. The results of their research were presented in the form of a native model of art curriculum in elementary school. The model derived from their research had three parts: basics, principles and elements, which in the basics section, philosophical foundations, sociological foundations and psychological foundations. After that, 9 principles of the model are presented, which are the principles of attractiveness, diversification, balance of human aestheticism and psychological principles, imagination principles, creativity and flexibility of human beauty and psychological principles and the principle of sublimation, have been obtained.

In a study entitled "Obstacles to the implementation of art lessons from the perspective of primary school teachers in Isfahan, tabatabaie, abbasi, mortaheb (2016), showed that teachers 'negative attitude, lack of specialized teachers, teachers' unfamiliarity with appropriate teaching methods, lack of appropriate facilities and inappropriate evaluation The art course is too moderate; the lack of awareness of school principals about the role of the art medium, the negligence of the planners and officials, and the ignorance of the students' parents about the importance of the art course are less than average. In connection with enriching the teaching of mathematics with the visual arts: The impact on the ability of elementary school students in geometry and the visual arts Schoevers, Leseman, Kroesbergen (2019) also concluded that research math, art and creativity in education to change practice Educationally designed. The program aims to teach specific learning objectives and a wide range of visual arts and geometry, and to promote students' creative skills and create opportunities for creativity in the visual arts and geometry. 
Steele (2019) in a study entitled "What is the intellectual feedback of graduates of an elementary school of art in the field of art, school, self and others?" It was concluded that the patterns of continuous participation of participants in art, including participation in artistic gatherings and the development of artistic sensitivities, were convergent. They valued the school and the teachers who provided them with a variety of methods and materials. Finally, participants attributed social skills (such as self-confidence, community, and communication) to their early experiences in an art integration school. In line with the theories mentioned above, Huzjak \& Županić Benić (2017) in measuring creativity in the teaching method of visual arts in primary school "concluded that the collaboration between educators and university professors and students of the School of Teacher Education within the methodology course teaching visual arts affects students' creativity.

Iwai (2013) in a review entitled "Considerations of Art Education in Children's Lives" presented in the framework of UNESCO report, points out that the relationship between art and education is significant from five perspectives: aesthetic development, socio-emotional development, Socio-cultural development, cognitive development, academic achievement. The results of this study show that proper artistic activities not only improve children's aesthetic development but also strengthen their appreciation for art. Children were able to gain better insights into self-expression, self-acceptance, acceptance of others, and selfawareness through role-playing and storytelling. Therefore, considering that the aim of the present study was to design and validate the art teaching model for elementary students, the question is what is the appropriate art teaching model for elementary students who have the appropriate credibility?

\section{Methodology}

In terms of practical purpose, in terms of data collection, the present study is a descriptive correlation and in terms of qualitative research method, in which the content analysis method has been used. This research is aimed at designing the model and using this qualitative method, the dimensions, components and indicators of the art teaching model were obtained. The scope of research in the analysis of art texts is as follows: 1. Articles available in reputable databases and websites; 2. Authoritative books, treatises and dissertations in the field of art teaching that have been used for analysis. The statistical sample in the qualitative part of the study, in the method of thematic analysis, is 54 articles or dissertations or dissertations in this field, all of which have been studied. The present study was used by qualitative research method, thematic analysis method with exploratory inductive approach to extract themes and template formats.

To get acquainted with the data, the researcher first collected a collection of texts available in the field of evolutionary learning. These texts included English and Persian articles as well as books related to art teaching. The advantage of data collection by the researcher is that when analyzing, he uses the knowledge and basic analytical basis to study the collected data several times and provides a preliminary list of ideas in the data and their noteworthy points. In the first stage of coding, the researcher discovered 8 comprehensive themes, 28 organizational themes and 71 basic themes, and in the second coding, he discovered 7 comprehensive themes, 24 organizational themes, and 65 basic themes. Finally, 7 comprehensive themes, 24 organizational themes and 61 basic themes were obtained. 
Table1. Final themes obtained from the content analysis of texts related to art teaching

\begin{tabular}{|c|c|c|c|}
\hline Row & Inclusive topics & Organizational themes & Basic themes \\
\hline \multirow{8}{*}{1} & \multirow{8}{*}{$\begin{array}{l}\text { teaching } \\
\text { method }\end{array}$} & \multirow{5}{*}{ Group } & Method of teaching innovation \\
\hline & & & Question and answer method \\
\hline & & & Explanatory method \\
\hline & & & Intergroup interaction \\
\hline & & & Role play method \\
\hline & & \multirow{3}{*}{ Solo } & Narrative \\
\hline & & & Direct training \\
\hline & & & Develop visual and auditory skills \\
\hline \multirow{19}{*}{2} & \multirow{19}{*}{ student } & \multirow{4}{*}{ Knowledge } & Familiarity with nature \\
\hline & & & Familiarity with art disciplines \\
\hline & & & Familiarity with tools and materials \\
\hline & & & Familiarity with cultural heritage \\
\hline & & \multirow{4}{*}{ Attitude } & The desire to gain experience in various fields \\
\hline & & & Interest in exploration in various fields of art \\
\hline & & & Attention to cultural heritage and respect for artists and works of art \\
\hline & & & Pay attention to your abilities and gain confidence \\
\hline & & \multirow{10}{*}{ Skill } & Develop sensory skills \\
\hline & & & Develop motor skills \\
\hline & & & Develop thinking skills \\
\hline & & & Ability to express thoughts and feelings in the form of art \\
\hline & & & Develop social skills \\
\hline & & & Individual \\
\hline & & & Spatial \\
\hline & & & Naturalistic \\
\hline & & & Musical \\
\hline & & & social \\
\hline & & Thinking & Creative Thinking \\
\hline \multirow{4}{*}{3} & \multirow{4}{*}{ Teacher } & \multirow[t]{2}{*}{ teaching method } & Pay attention to individual differences \\
\hline & & & Creativity \\
\hline & & \multirow{2}{*}{$\begin{array}{l}\text { Scientific development } \\
\text { and promotion }\end{array}$} & Develop teachers' professional competencies \\
\hline & & & Exchange of teacher experiences \\
\hline \multirow{4}{*}{4} & \multirow{4}{*}{ Opportunities } & \multirow{3}{*}{ Culture, heritage and art } & Pay attention to national culture and its heritage \\
\hline & & & Support for art education development programs with educational \\
\hline & & & approaches from cultural centers \\
\hline & & Art in society & $\begin{array}{l}\text { Progress and excellence of the people of the society with the help of } \\
\text { the language of art }\end{array}$ \\
\hline \multirow{14}{*}{5} & \multirow{14}{*}{ weak points } & \multirow{4}{*}{ Parents } & Weakness in valuing art \\
\hline & & & Lack of parental welcome \\
\hline & & & Parental ignorance \\
\hline & & & High expectations and expectations of parents in getting grades \\
\hline & & \multirow{3}{*}{ Educational } & Lack of specialized teachers \\
\hline & & & Lack of training hours \\
\hline & & & Weakness in textbooks \\
\hline & & Time & Incompatibility of content and time \\
\hline & & Location & $\begin{array}{l}\text { Lack of appropriate educational space for displaying students' works } \\
\text { (holding Zhojman in a suitable space) and learning process }\end{array}$ \\
\hline & & \multirow[t]{2}{*}{ Equipment } & Lack of proper equipment \\
\hline & & & Don't use new technologies \\
\hline & & & Lack of content enrichment \\
\hline & & Books & Lack of connection between goals and content \\
\hline & & & Intercourse \\
\hline
\end{tabular}




\begin{tabular}{|c|c|c|c|}
\hline \multirow{3}{*}{6} & \multirow{3}{*}{ Strengths } & Upstream documents & $\begin{array}{l}\text { Pay special attention to artistic education in the document of } \\
\text { fundamental change in Iran }\end{array}$ \\
\hline & & The place of art & Promoting the place of art in education \\
\hline & & Audience attention & High audience interest in program content \\
\hline \multirow{9}{*}{7} & \multirow{9}{*}{ Principles } & \multirow{2}{*}{$\begin{array}{l}\text { The principle of } \\
\text { moderation }\end{array}$} & Beauty \\
\hline & & & Perfectionism \\
\hline & & \multirow{4}{*}{ The principle of creation } & Imagination \\
\hline & & & Creativity \\
\hline & & & flexibility \\
\hline & & & Creating Beauty \\
\hline & & \multirow[t]{2}{*}{ Combining art with goals } & Combining artistic activities with educational topics and goals \\
\hline & & & Having different goals of art education \\
\hline & & The principle of freedom & Freedom for innovation and creativity \\
\hline
\end{tabular}

After identifying the comprehensive, organizational, and basic themes, the Credit Credit Questionnaire was prepared and educational experts, including 14 academic experts, were asked about each of the topics. Experts were also asked to state whether the theme should be added or corrected. The purpose of this researcher-made questionnaire was to study the design and validation of the art teaching model in the elementary school of Iran. Then, for each topic, the index of narrative-content ratio was calculated. In this index, experts in the field of transformational learning were used and by expressing the operational definitions of the topics, they were asked to classify each question based on the Likert spectrum. The three parts of this spectrum are: 1 . the word is necessary; 2. the word is useful, but not necessary; 3 . the word is not necessary. Then, based on the following formula, the narrative-content ratio was calculated. 14 specialists in educational sciences and psychology completed the questionnaire. According to the number of experts who evaluated the questions, the minimum acceptable CVR value should be 0.62 . Subjects for which the calculated CVR value is less than the amount specified by the number of experts evaluating the question should be discarded, because according to the content validity index, they do not have acceptable content validity (Hajizadeh, Asghari, 2015).

The group of experts was a group of specialists in the field of educational sciences who had sufficient knowledge about teaching and learning art and the various dimensions and aspects of teaching and learning. According to the calculation of the relative content coefficient for single items, 71 basic themes were obtained first and 65 basic themes were approved in the second coding. After determining CVR and reviewing experts, $4 \mathrm{CVR}$ basic themes were less than 0.62 was not approved by experts and specialists, and finally 61 subjects received CVR above 0.62 and were approved by experts and specialists. In this research, first, coding was done by studying books and articles in the field of art teaching and then coding was done again and approved by professors and experts. After two coding steps, 71 basic themes were discovered and finally 61 basic themes were discovered. The approval of experts and specialists arrived. Then, the results of these two codes were compared with each other and the holistic method was used to calculate the reliability. In this study, the percentage of agreement is 0.89 .

\section{Findings}

In the present study, data analysis method with inductive exploratory approach was used to analyze the data. To this end, we first tried to determine the themes in the text by studying the raw data in general. In this study, each topic, according to its subject and meaning, is a set of sentences that has its own meaning. To derive this meaning, first the texts related to teaching art were identified and finally, by studying and coding the identified articles and books, 61 themes were extracted as basic themes and 24 themed themes and 7 comprehensive themes were extracted. After discovering the themes, a questionnaire was prepared using the thematic analysis method with an inductive approach and by extracting the dimensions, 
components and indicators of art teaching, and informed the experts in the field of educational sciences, psychology and art education. The conceptual diagram of the present research findings is presented from Figure 1 to Figure 5 along with the proposed model of inclusive and organizational themes (Figure 6) of the present study.

Based on the findings of the present study, the first comprehensive theme obtained from the analysis of the themes of art teaching patterns is its various teaching methods. The teaching method is a regular, logical and logical way to present the lesson. According to Figure 1 and the findings of the present study, these methods can be divided into two categories: individual methods and group methods. The basic ones are: the narrative method, which was based on literature, and the direct teaching method, which is based on experience, as well as the method of cultivating visual-auditory skills. Be. According to the analysis, the narrative method includes storytelling, poetry reading, coloring and drawing lines in the first grade, completing the play and semi-finished storytelling, telling creative stories, and direct teaching methods include using colors in nature, using From the leaves of trees and flowers, making handicrafts with leaves and flowers, using pantomime, working with color, collecting stones and flowers and plants, painting with natural colors, painting with stones, visiting nature (yard School) and in general it can be said that acquaintance with nature and the greatness of God. Figure 1 shows a conceptual diagram of the art teaching method in elementary school.

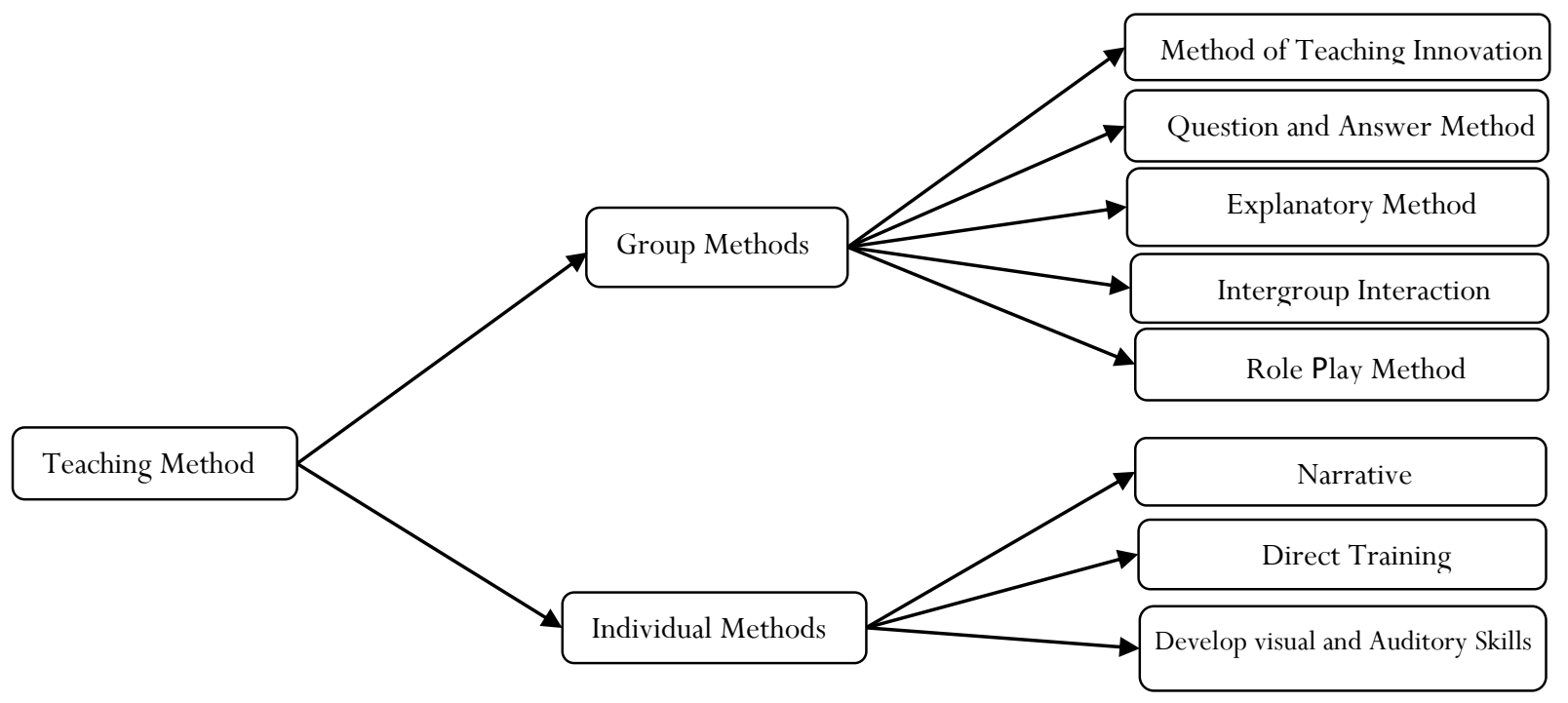

Figure1. Index of teaching methods and dimensions and items of art teaching methods in elementary school

Another indicator related to the analysis of topics related to be teaching is related to students. From the indicators of students' index, knowledge, attitude, skills and thinking have been obtained. The dimension of knowledge includes familiarity with nature, familiarity with art disciplines, familiarity with tools and materials and familiarity with cultural heritage, and then attitude includes the desire to gain experience in different disciplines, interest in exploration in various fields of art, attention to Cultural heritage and respect for artists and works of art and attention to their abilities and gaining self-confidence, and then the skills include developing skills of sensory skills, development of motor skills, development of thinking abilities, ability to express thoughts and feelings in the form of art, development of social skills. Intrapersonal, spatial, naturalistic, musical, and social, and then thought, including c Wow, its creative thinking. 


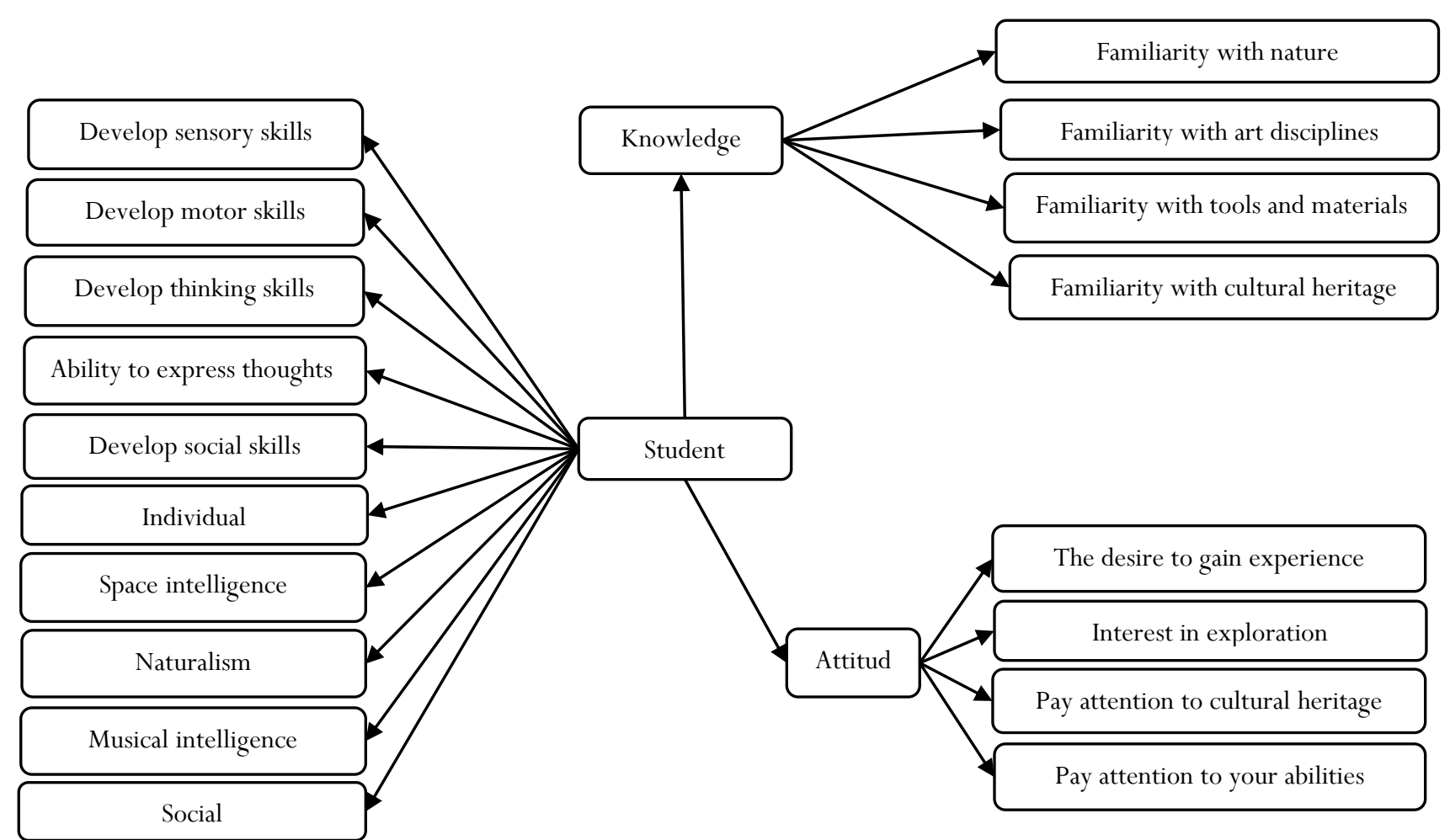

Figure2. Student Index and its related dimensions and items

Another indicator of the analysis of topics related to art teaching is the teacher, which includes the dimensions of teaching methods and the development and scientific promotion of teachers. Then, the teaching method includes attention to individual differences and fostering creativity, and then the development and scientific promotion of teachers has included the development of teachers 'professional competencies and the exchange of teachers' experiences.

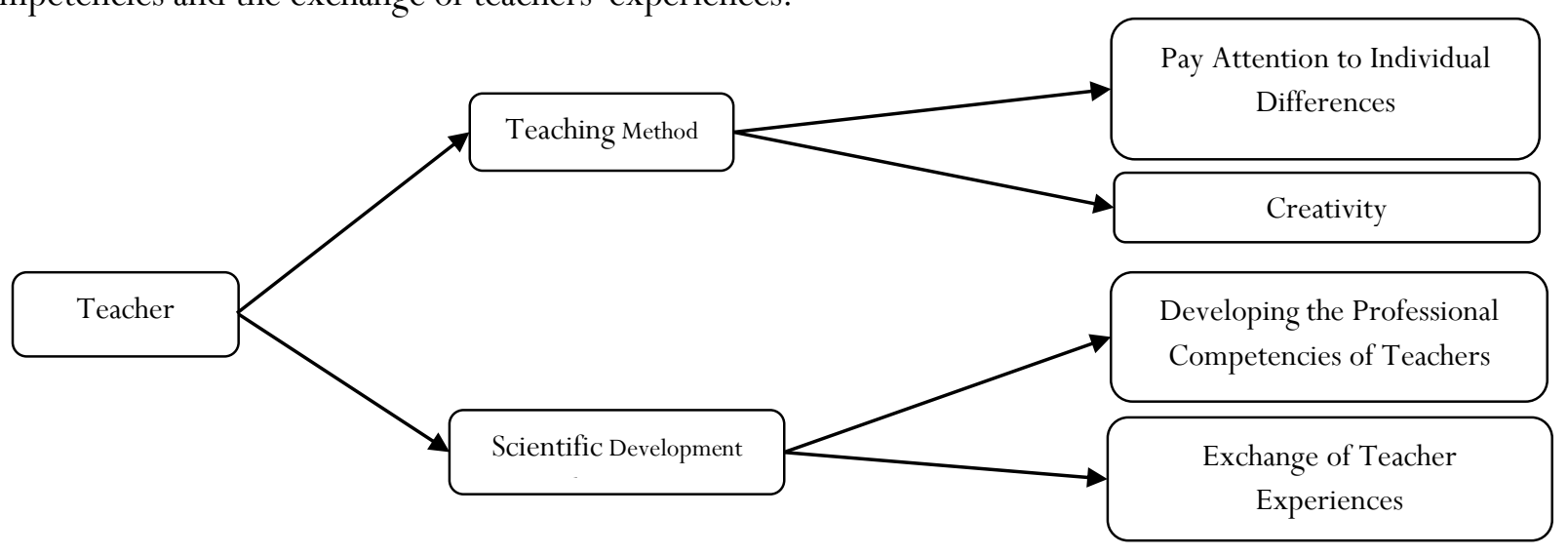

Figure3. Teacher index and its dimensions and expressions

The fourth indicator is the opportunities that include the dimensions of culture, heritage, and art and society in society. The dimension of culture, heritage and art includes the issues of attention to national culture and its heritage and support for the development of art education development programs with educational approaches by cultural centers. Figure 4 shows the conceptual diagram of the opportunities obtained from the analysis of art teaching topics in the elementary school. 


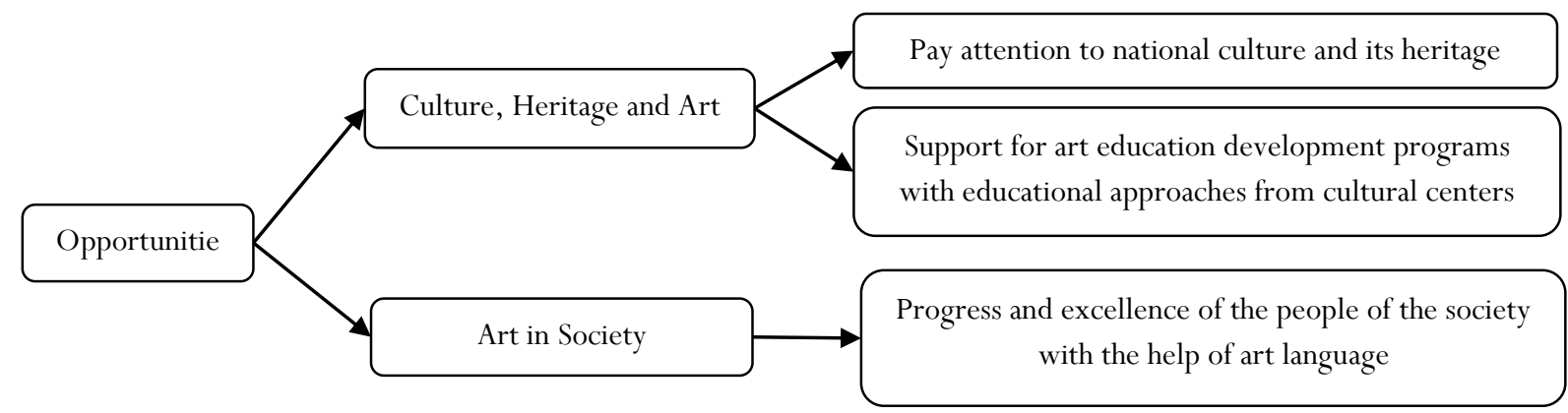

Figure4. Index of opportunities and its dimensions and angles

The last fifth indicator is the weaknesses related to teaching art in the primary education of Iran, which includes the dimensions of parents, education, time, place, equipment and books, and then the parents related to the weaknesses in art evaluation, lack of acceptance. Parents' ignorance of parents, high expectations and expectations of parents in getting grades, and then education includes the items of lack of specialized teachers, lack of teaching hours and weakness in textbooks and then time is related to the mismatch of content and time, and then the relevant place. Lack of appropriate educational space for displaying students' works (holding Zhojman in a suitable space) and learning process The equipment then includes items that do not have the proper equipment and do not use new technologies, and then books that do not include content enrichment, lack of connection between goals and content, and confusion. 


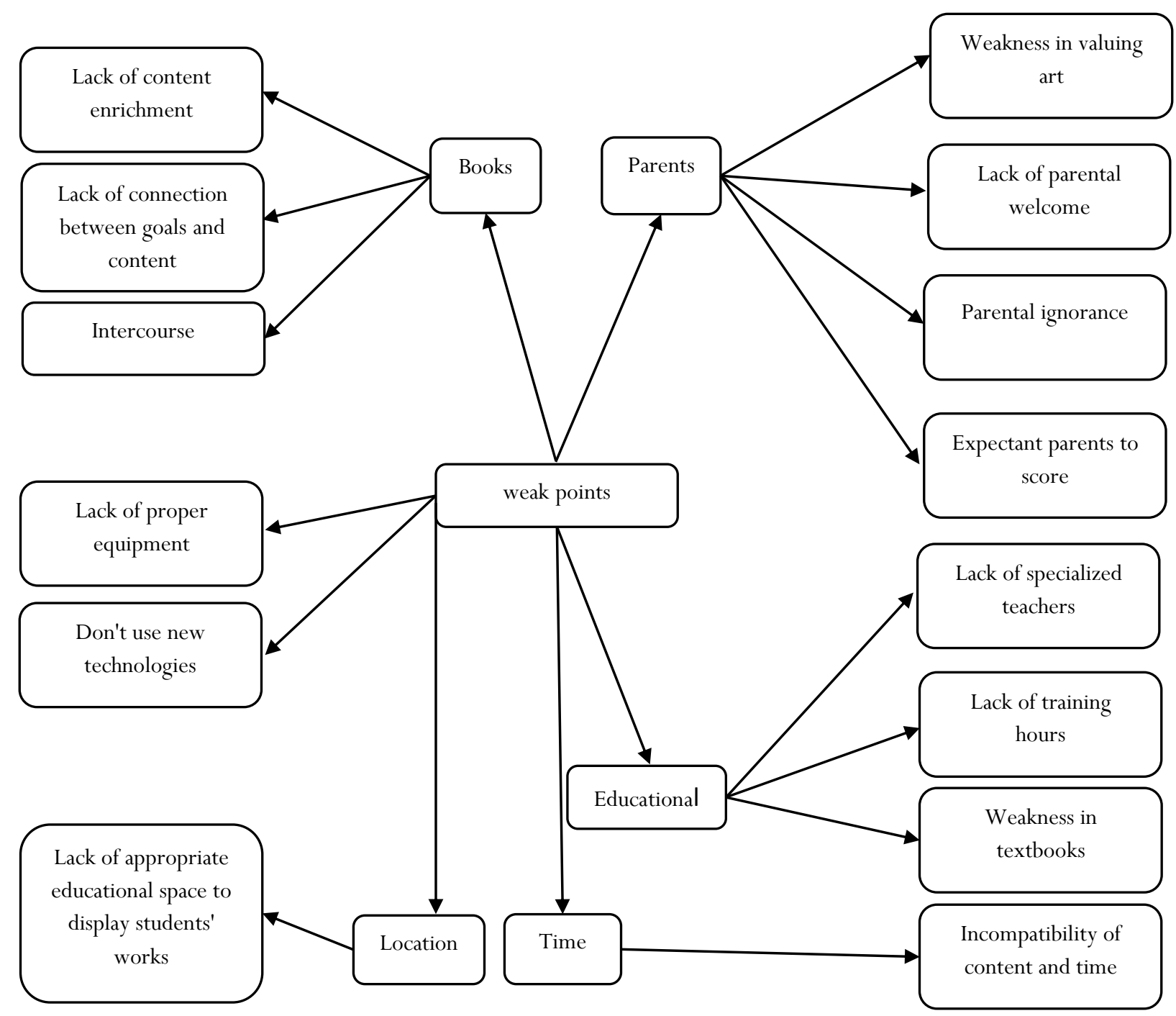

Figure5. Index of the weaknesses of art teaching in the elementary school of Iran and the dimensions and related discourses

The sixth indicator for analyzing the themes of art teaching patterns is the strengths of art teaching, which has the dimensions of upstream documents, the position of art and the audience's attention. Then the upstream documents include a special attention to art education in the document of fundamental change in Iran, and then the position of art includes the promotion of the position of art in education, and then the audience's attention includes the attention and interest of the audience to the content of the program. Figure 6 shows the strengths of the themes analysis of art teaching patterns in the elementary school, along with its dimensions and narratives. 


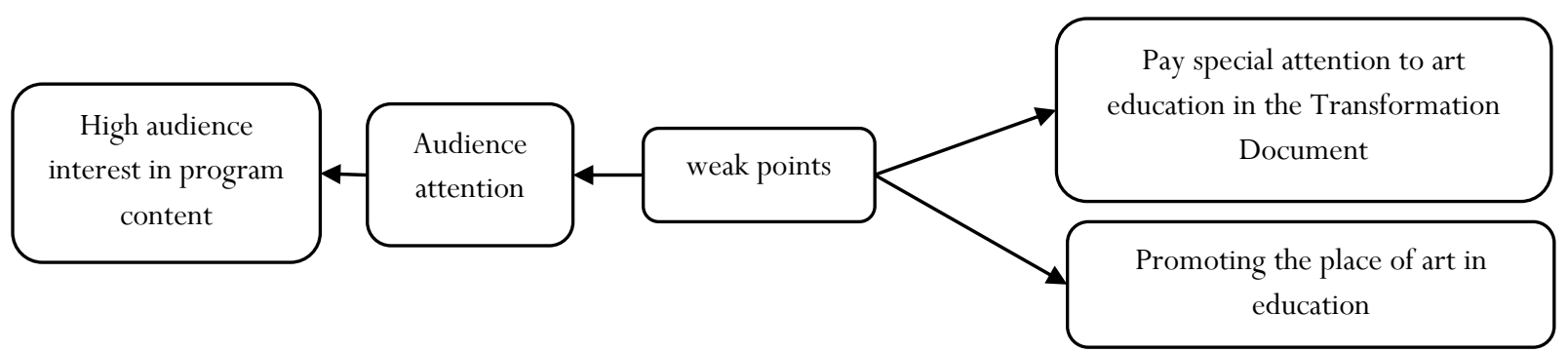

Figure6. Index of the strengths of teaching art in the elementary school of Iran and the dimensions and related discourses

The last and seventh indicators obtained from the analysis of themes related to teaching art are its principles, which include the principle of moderation, the principle of creation, combining art with goals and the principle of freedom. It includes imagination, creativity, flexibility and beauty. Figure 7 shows the index of principles derived from the analysis of art teaching topics in the elementary school of Iran and the dimensions and related discourses.

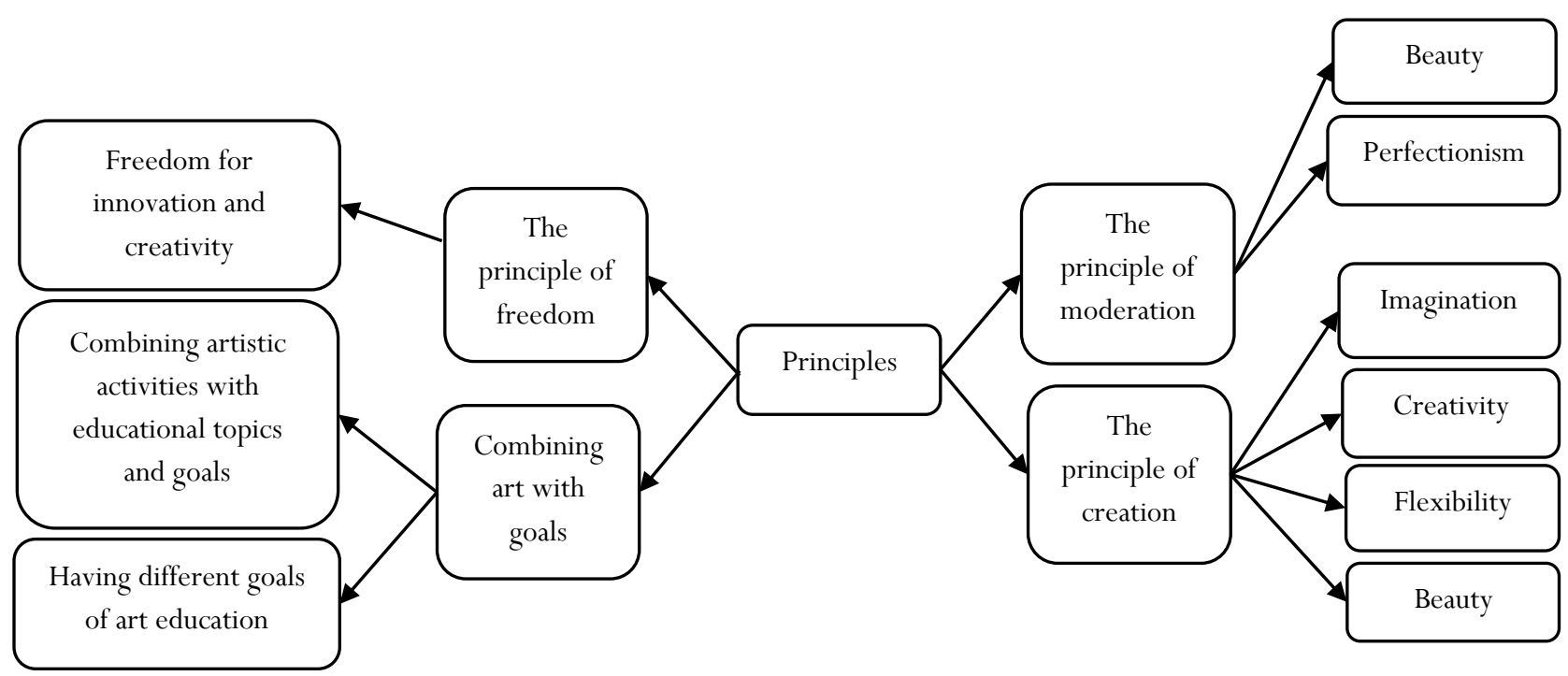

Figure7. Index of principles derived from the analysis of art teaching topics in the elementary period of Iran and its related dimensions and discourses.

\section{Discussion}

The findings of the present study showed that the indicators of the art teaching model in the primary period of Iran are: 1- Teaching method which includes group dimensions (novel teaching method, question and answer method, explanatory method and intergroup interaction), individual (narration, Direct education and development of visual and auditory skills), 2- A student who includes the dimensions of knowledge (familiarity with nature, familiarity with art disciplines, familiarity with tools and materials and familiarity with cultural heritage) and attitude (desire to gain experience in disciplines Different, interest in exploration in different fields of art, attention to cultural heritage and respect for artists and works of art and attention to their abilities and acquisition Confidence) and skills (development of sensory skills, development of motor skills, development of thinking abilities, ability to express thoughts and feelings in the form of art of developing social skills) and intelligence (intrapersonal, spatial, naturalistic, musical and social) and thinking (thinking). Creative), 3- Teacher that includes the dimensions of teaching methods (attention to individual differences and cultivation of creativity) and scientific development and promotion (development of teachers 'professional competencies and exchange of teachers' experiences), 4- Opportunities that include dimensions 
of culture, heritage and art (Attention to national culture and its heritage and support for art education development programs with educational approaches by cultural centers) and art in society (progress and excellence People in the community with the help of the language of art), 5- Weaknesses that include the dimensions of parents (weakness in appreciation of art, lack of acceptance of parents, ignorance of parents and expectation and high expectations of parents in grading), educational (lack of specialized teachers, lack of teaching hours And weakness in textbooks), time (inconsistency of content and time), place (lack of appropriate educational space), equipment (lack of proper equipment) and books (lack of content enrichment, lack of connection between goals and content and fusion) 6- Strengths that include upstream documents (special attention to art education in the document of fundamental change in Iran) and the position of art (promotion of the position of art in education), 7- Principles that include the principle of moderation (beautiful Pessimism and perfectionism), the principle of creation (imagination, creativity, flexibility and aesthetics), combining art with goals (combining artistic activities with educational topics and goals and having different goals of art education) and the principle of freedom (freedom for innovation and Creativity). In line with the alignment and inconsistency of the results of the present study with other studies can be said.

Ghaffari, et all (2017) showed that the disciplinary art education curriculum in the field of art production and critique has no effect on students 'artistic education, but the disciplinary art education curriculum in the field of art history and aesthetics has an effect on students' art education. Also, Ghanbari, Hemmati (2016) showed that in the art curriculum of the first grades until the beginning of the elementary school, attention has been paid to the components of aesthetics. The principle of creation is and is one of the indicators of principles, so with the present research Sue said. Farsi and Nouri (2016) concluded that in the field of art education, individual differences between students should be considered and due to the lack of trained manpower in the field of art education and their insufficient familiarity with the principles of art teaching, holding training courses for Teachers, as well as the teaching of art teachers with the specialization of art education in teacher training institutes and faculties of educational sciences, are necessary, so in this regard, individual differences in the research present in the teacher index, the teaching method has been addressed and weaknesses The educational dimension addresses the shortage of specialized teachers. Therefore, the present study was consistent with Farsi and Nouri (2016) research, Garmabi, et al. (2015) showed that in teaching art, the balance of human aestheticism, principles of imagination, creativity and flexibility of human beauty and psychological foundations and the principle of sublimation have also been obtained from the perfection of real beauty and art. The perspective of aesthetics and aestheticism and perfectionism has been in line with the present study.

Tabatabai, et all (2016) showed that teachers 'negative attitude, lack of specialized teachers, teachers' unfamiliarity with appropriate teaching methods, lack of appropriate facilities and inappropriate evaluation of art lessons, more than average; lack of awareness of school principals about the role of art in average The negligence of planners and officials, and the ignorance of parents of students about the importance of art lessons, are less than average to prevent the correct implementation of art lessons, which is consistent with the present study. Schoevers, et all (2019) concluded that art can be effective in promoting students' creative skills and creating opportunities for creativity, and therefore the perspective of creativity in this research has been consistent with this dimension. Steele (2019) showed that an art school can be effective in social skills (such as self-confidence, community and communication) and in the present study, social skills have been developed in the dimension of skills and therefore steele research (2019). It has been consistent with the present study.

Huzjak, Županić Benić (2017) concluded that appropriate teaching methodology in the arts can affect students' creativity, and therefore have been consistent with the present study in terms of their impact on creativity. Iwai (2013) shows that appropriate artistic activities not only improve children's aesthetic development but also strengthen their appreciation for art, and therefore have been consistent with the 
present study from the perspective of children's aesthetics. When students work in the arts, they are in fact personal experiences and narratives that are not seen in other areas of learning, and this requires capable teachers. Teacher awareness of students 'abilities and weaknesses provides educational experiences that help discover students' creativity. Teachers need to have enough knowledge about the arts that this knowledge is needed to make the right judgments about student learning. According to the researcher, using the analysis of themes of art teaching methods in elementary school can help teachers to create art learning opportunities. In this way, teachers are most expected to create rich and varied activities and experiences in accordance with the factors and elements of the curriculum and the needs of students for better teaching. Through the analysis of art themes, the activities and content of the art curriculum make it possible to apply the global and indigenous approaches to the art curriculum. The art course provides an opportunity to cultivate a sense of aesthetics and creativity and to facilitate teach other subjects, to express emotions freely, to explore emotional and behavioral problems, and to provide personal experiences. And to improve the implementation of the art curriculum, especially in the elementary school, and given that most of the knowledge is gained in the classroom and the classroom and the quality of teaching is the most important factor in student progress, teachers should work to improve the quality of teaching.

According to the findings of the present study, factors have caused teachers to encounter problems and obstacles in achieving the intended goals, which in this research has been called as weaknesses, including the lack of equipment and a suitable place for teaching art has been proposed. Lack of time for art classes makes it impossible to engage in art on a large scale, and teachers have to be content with very simple paintings and handicrafts and avoid meditating on the art school curriculum. Parents' ignorance of the importance of the role of art in children's learning is another factor that has led to parents not being comfortable with school. However, teachers tried to make up for the lack of funding and facilities by being creative and providing the best they could. Art can be a good platform for children to become familiar with the traditions, Islamic and indigenous cultures, with the development of sensory skills, the ability to nurture children's creativity and social participation. Continuous review of the Teacher's Guide to Art Teacher's Guide and evaluation of teachers' performance and obtaining feedback from them intermittently and its application in how to compile a Guide to Art is effective in updating its content. Also, by training teachers specializing in the field of art and implementing the items mentioned in the upstream documents in the field of art, the weaknesses in this field can be covered and eliminated. Developing an art textbook that has the right to choose for students is another experience that can solve many problems and obstacles in teaching art.

One of the limitations of the present study is that the present study was in the field of teaching art in primary school and therefore its results cannot be generalized to other lower age groups and the results can be cited only for this age group. In general, through teaching art, you can explore children's skills, creativity, talent, intelligence, and imagination, and discover the hidden points in a child's mind and teach him to look at his surroundings with a new perspective and with the capabilities around him. Make your imagination come true. Undoubtedly, school is a very important factor in cultivating talent and creating creativity. Art disciplines are a means of expression and excellence that can have a significant impact on increasing the abilities and growth of children's creative power at this age. The arts can play an important role in life, even in healing. The concept of art therapy is based on the assumption that the expression of emotion in art has a healing effect. Encouraging children to do artistic work and creating an environment full of peace and avoiding a specific pattern in teaching, for the child, in schools, causes hidden talents in the child and helps the child's mental and physical development and produces new and innovative ideas. Given the importance of art, the role of the teacher in the process of teaching art is very important and it is better to give the necessary training to teachers. Presenting teaching methods for this age group with teaching methods and with lesson plans to schools that do not have art teachers, organizing teaching methods festivals in a very serious and continuous manner during the holiday season among teachers and educators, art students and families. 
Therefore, based on the findings of the present study, it is suggested that efficient teachers are expected to have the following abilities and characteristics to teach art: 1- Know the content of art curriculum and identify and assign appropriate educational materials, tasks and activities suitable for teaching situations. - Be able to learn special skills and have the necessary creativity. 2- To create creative and useful learning in the field of environmental art. 3- To manage their classroom according to the individual and group learning needs of the students and considering the selected aspects of the students' performance and their mental and social background. 4- Effective and appropriate cooperation with the colleagues, parents and other people. Have a community. 


\section{References}

Alaghband A. (2018). Introduction to Educational Management, Psychic Publishing, 220 pages.

Amini M. (2001). Designing the optimal model of art education curriculum in elementary school and in comparison with the current situation, $\mathrm{PhD}$ thesis, Tarbiat Modares University.

Asensio-Pérez J I, Dimitriadis Y, Pozzi F, Hernández-Leo D, et all. (2017). Towards teaching as design: exploring the interplay between full-lifecycle learning design tooling and teacher professional development. Computers \& Education, 114(1): 92-116.

Bazargan A. (2016). An Introduction to Qualitative and Mixed Research Methods; Common Approaches in Behavioral Sciences, Didar Publications, Sixth Edition, Tehran, 237 pages.

Ceresia F. (2016). Sunny Island. An interactive learning environment to promote systems thinking education for primary school students. Procedia-Social and Behavioral Sciences, 237(5): 980-985.

Dilekli D, Tezci E. (2016). The relationship among teachers' classroom practices for teaching thinking skills, teachers' self-efficacy towards teaching thinking skills and teachers' teaching styles, Thinking Skills and Creativity, 4(1): 144151.

Farsi S, Nouri A. (2016). Evaluation of elementary school art curriculum by expertise and educational methods, Quarterly Journal of Education, 32(1): 1-10.

Gal M, Borg W, Gal J. (2015). Quantitative and qualitative research methods in psychology and educational sciences (translated by Ahmad Reza Nasr and others). Tehran: Samat Publications. 3(1): 524-530.

Garmabi H A, Maleki H, Beheshti S, Afhami R. (2015). Designing and validating the native pattern of the elementary school curriculum based on the components of aesthetics and art. Quarterly Journal of Preschool and Elementary Studies, 1(2): 1-10.

Ghaffari Kh, Kazempour I, Oghati Hamedani M. (2017). Discipline-oriented art education curriculum, Quarterly Journal of Research in Curriculum Planning, Thirteenth Year, 2(25): 98-110.

Ghanbari S, Hemmati M. (2016). The relationship between social capital and job performance of employees of Bu Ali Sina University. Quarterly Journal of Higher Education, 9 (35): 115-133.

Hajizadeh E, Asghari M. (2015). Methods and statistical analyzes by looking at research methods in biological and health sciences. Jihad Daneshgahi Publishing Organization.

Huzjak M, Županić Benić M. (2017). Measuring Creativity in Visual Arts Teaching Methodology in Elementary School. Croatian Journal of Education: Hrvatski časopis za odgoj i obrazovanje, 19(3): 43-59.

Iwai K. (2013). The Contribution of Arts Education to Children's Lives, Paper presented at Preparedness for Teaching Art. International Journal of Education \& the Arts, 8 (5): 5-10.

Mehr Mohammadi M, Kian M. (2018). Curriculum and Art Education in Education, Organization for the Study and Compilation of University Humanities Books (Samt), Tehran, 400 pages.

Sawyer R K. (2017). Teaching creativity in art and design studio classes: A systematic literature review, Educational Research Review, 9(1): 99-113.

Schoevers E M, Leseman P P, Kroesbergen E H. (2019). Enriching Mathematics Education with Visual Arts: Effects on Elementary School Students' Ability in Geometry and Visual Arts. International Journal of Science and Mathematics Education, 1(4): 1-22.

Steele J S. (2019). Where are They Now? Graduates of an Arts Integration Elementary School Reflect on Art, School, Self and Others. International Journal of Education \& the Arts, 20(11):20-30.

tabatabaie M, abbasi P, mortaheb A. (2016). Study of Performing Barriers of Art Lessons from the Viewpoints of the Primary School Teachers of Isfahan. Studies of Early Childhood and Elementary Education, 1(3): 1-15.

Taşdemir V N. (2010). Attitudes of the students of primary education class teaching department to the visual Arts Education Course. Procedia-Social and Behavioral Sciences, 2(2): 2572-2576.

Winch C. (2010). Teaching thinking: key debates in educational policy. In C. Winch (Ed), Afterword. London, UK: Continuum Press. 1(1): 102- 114. 